\title{
Vitrectomy for Complicated Retinal Detachment Without the Use of Perfluorocarbon Liquid: A Real- World Data and Retrospective Study
}

\author{
Ye Bai · Qi Song · Jing Liu • Qin-Xing Wu • Xue-Jiao Qin
}

Received: December 30, 2021 / Accepted: February 3, 2022 / Published online: February 23, 2022

(C) The Author(s) 2022

\begin{abstract}
Introduction: This study aimed to evaluate the effectiveness of vitrectomy without using perfluorocarbon liquid (PFCL) for the treatment of complicated retinal detachment (RD).
\end{abstract}

Ye Bai and Qi Song have contributed equally to this paper.

Supplementary Information The online version contains supplementary material available at https:// doi.org/10.1007/s40123-022-00479-x.

Y. Bai · X.-J. Qin (ه)

Eye Centre of Shandong University, The Second Hospital of Shandong University, No. 247 Beiyuan Street, Jinan 250012, Shandong, People's Republic of China

e-mail: qinxuejiao@hotmail.com

Y. Bai

Department of Ophthalmology, Xi'an People's

Hospital, Xi'an, People's Republic of China

Q. Song

Department of Operating Theatre, Qilu Hospital of Shandong University, Jinan, People's Republic of China

J. Liu

Department of Biostatistics, School of Public Health, Cheeloo College of Medicine, Shandong University, Jinan, People's Republic of China

\section{Q.-X. Wu}

Department of Ophthalmology, The Second Affiliated Hospital of Shandong First Medical University, Taian, People's Republic of China
Methods: The utilisation of PFCL was calculated in four hospitals in 2020 and in one hospital every year from 2012 to 2020 . A case series of 320 RD eyes treated with vitrectomy without the use of perfluorocarbon liquid (VWTPL) was followed up for 1-26 months. The rate of retinal reattachment (RR) and postoperative visual acuity (VA, LogMAR) was evaluated. Furthermore, factors influencing RR and VA were analysed.

Results: The overall utilisation of PFCL was $43.87 \%$ (42.74\%, 45.83\%, 62.39\% and $4.5 \%$ ). The annual utilisation was $46.94 \%, 20.43 \%$, $46.73 \%, 47.41 \%, 20 \%, 17.24 \%, 7.60 \%, 10.67 \%$ and $4.49 \%$ from 2012 to 2020 . The VA of 320 eyes improved from $1.96 \pm 1.07$ preoperatively to $1.43 \pm 0.92$ (LogMAR, $p<0.001) 1$ week post-operation. In the follow-up of 1-26 months (median: 9 months), the primary and final RR was $87.37 \%$ and $95.56 \%$, respectively. Age, uveitis, recurrent RD, the number of detached retinal quadrants, aPVR and preoperative VA were considered as the factors influencing postoperative VA. Moreover, preoperative VA and preoperative intraocular pressure were the factors influencing RR.

Conclusion: The utilisation of PFCL varies amongst hospitals with a highest percentage of $62.39 \%$. VWTPL is safe and effective, thereby saving costs and preventing complications related to PFCL.

Trial Registration: ChiCTR-ORC-17014225. 
Keywords: Complicated Retinal Detachment; Non-Application; Perfluorocarbon Liquids; Real-World Data; Vitrectomy

\section{Key Summary Points}

Why carry out this study?

Since its introduction in the 1980s, perfluorocarbon liquid has been widely used in vitrectomy surgery, particularly for complicated retinal detachment. This could be illustrated by the real-world data in our study. Although perfluorocarbon liquid is a useful 'liquid tool', it causes some troublesome complications as well as economic costs

With the development of delicate surgical instruments, it is possible to replace intraoperative perfluorocarbon liquid by surgical technique, such as air-fluid exchange, to flatten the detached retina

\section{What was learned from the study?}

The utilisation of perfluorocarbon liquid varies from 4.5 to $62.39 \%$ amongst hospitals. The primary and final retinal reattachment rate in those treated by vitrectomy without the use of perfluorocarbon liquid is not lower than those previously reported

Vitrectomy for complex retinal detachment can be performed without perfluorocarbon liquid

\section{DIGITAL FEATURES}

This article is published with digital features, including videos, to facilitate understanding of the article. To view digital features for this article, go to https://doi.org/10.6084/m9. figshare. 19115708.

\section{INTRODUCTION}

Pars plana vitrectomy (PPV) is an effective surgical procedure for complicated retinal detachment (CRD). CRD refers to retinal detachment (RD) accompanied with other pathological ocular conditions, including high myopia, ocular trauma, choroid diseases, giant retinal tear, macular hole, history of cataract surgery, history of vitrectomy, severe proliferative vitreoretinopathy (PVR), intraocular inflammation, systemic immune diseases and systemic or ocular tumours. CRDs are difficult to manage, and most cases are treated by PPV or the combination of scleral buckling (SB) and PPV [1-4].

Given its high specific gravity, moderate surface tension, low viscosity and optical transparency, perfluorocarbon liquid (PFCL) was introduced in PPV in the 1980s [5], and it was primarily used to smooth out and fix the retina in CRDs [6]. PFCLs are especially helpful for the treatment of macular-involved disorders [7]. Although PFCL is an important 'liquid tool', it causes some complications such as retention, inflammation [8], retinal shift [9], immigration to the subretinal area [10], anterior chamber or subarachnoid space $[11,12]$, damage to retinal cells [13] and blindness [14]. To date, there is no evidence about the feasibility of avoiding the use of PFCLs in the treatment of CRDs.

The development of delicate surgical instruments increases the safety and efficiency of vitrectomy, allowing smaller cuts, faster cutting and more stable intraocular pressure (IOP). Thus, replacing intraoperative PFCL by air-fluid exchange to flatten the detached retina is possible, given that the vitreous traction and epiretinal membrane are removed completely. This technique is called micro-vitrectomy without the aid of PFCL (VWTPL). VWTPL can prevent PFCL-related complications, shorten operation time and decrease medical expenses. In this study, we obtained real-world data of PFCL utilisation, evaluated the performance of VWTPL in the treatment of CRD and confirmed its applicability because of its successful postoperative retinal reattachment (RR) and improved visual acuity (VA). Factors influencing postoperative VA and RR were also analysed. 


\section{METHODS}

The study was approved by the Independent Ethics Committee on Scientific Research of Shandong University, Qilu Hospital (KLYY2017-247), and conducted in accordance with the Declaration of Helsinki. Signed informed consent was obtained from all participants and the parent or guardian for participants $<16$ years old.

\section{Case Selection}

Two kinds of cases were presented. The first case was selected to study the real-world utilisation of PFCL. Data were collected from four hospitals in 2020. Patients with RDs, who were treated by vitrectomy, were reviewed, and the use of PFCL was recorded. The same data were collected from 2012 to 2020 in one of the hospitals to explore the utilisation of PFCL every year. The four hospitals included one tertiary general hospital, one hospital focused on ophthalmology and two were local general hospitals. The proportion of PFCL applications was analysed.

The other case was collected to study the effectiveness of VWTPL. A case series of patients with CRD was collected from January 2017 to December 2020 at Qilu Hospital, Shandong University. The inclusion criterion is treatment by VWTPL (that is, without the intraoperative use of PFCL) operated on by one surgeon. Data were analysed to study the effectiveness and prognostic factors of this procedure. A total of 320 eyes from 320 patients were included. Of the 320 cases, 27 were lost to follow-up. Postoperative VA and primary and final RR rates were evaluated. Primary RR referred to the rate of retinal reattachment after the original surgery. Final RR referred to the rate of retinal reattachment at the end of follow-ups. For our patients, 1-week post-operation was a relatively fixed follow-up time point; in the following period, they might not visit the surgeon regularly, especially when the disease becomes stable or improves, so the data were most complete at 1-week post-operation.

\section{Surgical Procedure of VWTPL}

The common VWTPL procedure was conducted in the following sequence: PPV, complete removal of proliferative membrane and posterior vitreous membrane (with the aid of triamcinolone acetonide), air-fluid exchange, in situ photocoagulation and silicone oil tamponade (when necessary). The detached retina was smoothed out by simultaneous air-fluid exchange and subretinal fluid drainage from the hole (see video 1 in the online/HTML version of the manuscript). Triamcinolone acetonide was used in all cases to facilitate the dissection of the posterior vitreous adhesion or epiretinal membrane. In addition, 194 (60.63\%), 23 (7.19\%) and 39 (12.19\%) eyes were subjected to internal limiting membrane peeling, retinotomy and cataract phacoemulsification, respectively. If the retina failed to flatten intraoperatively by air-fluid exchange even after retinotomy, usually in cases with narrow funnel-shaped RD or continuous sub-retinal hemorrhage, then PFCL would be used, and this case would not be included in this study. After the surgery, 309, 3, 5 and 3 eyes had silicone oil, C3F8, sterile air and retained perfusion fluid without air-fluid exchange, respectively.

\section{Statistical Analyses}

All data were tested for normal distribution using the Kolmogorov-Smirnov test before analyses. Statistics were performed by IBM.SPSS.20 statistics.

Percentage of PFCL utilisation was tested by descriptive statistics and chi-square test. Preand postoperative VA (LogMAR) changes were tested using a paired $t$-test. All VAs referred to the best corrected VA.

The factors influencing the changes in VA were tested by chi-square test, ANOVA and Kruskal-Wallis test accordingly. The positive results were subjected to ordinal logistic regression to identify the factors predictive of postoperative VA.

In addition, the factors influencing RR were tested by chi-square test, Kruskal-Wallis test, $t$ test and Mann-Whitney $U$ test accordingly. The 

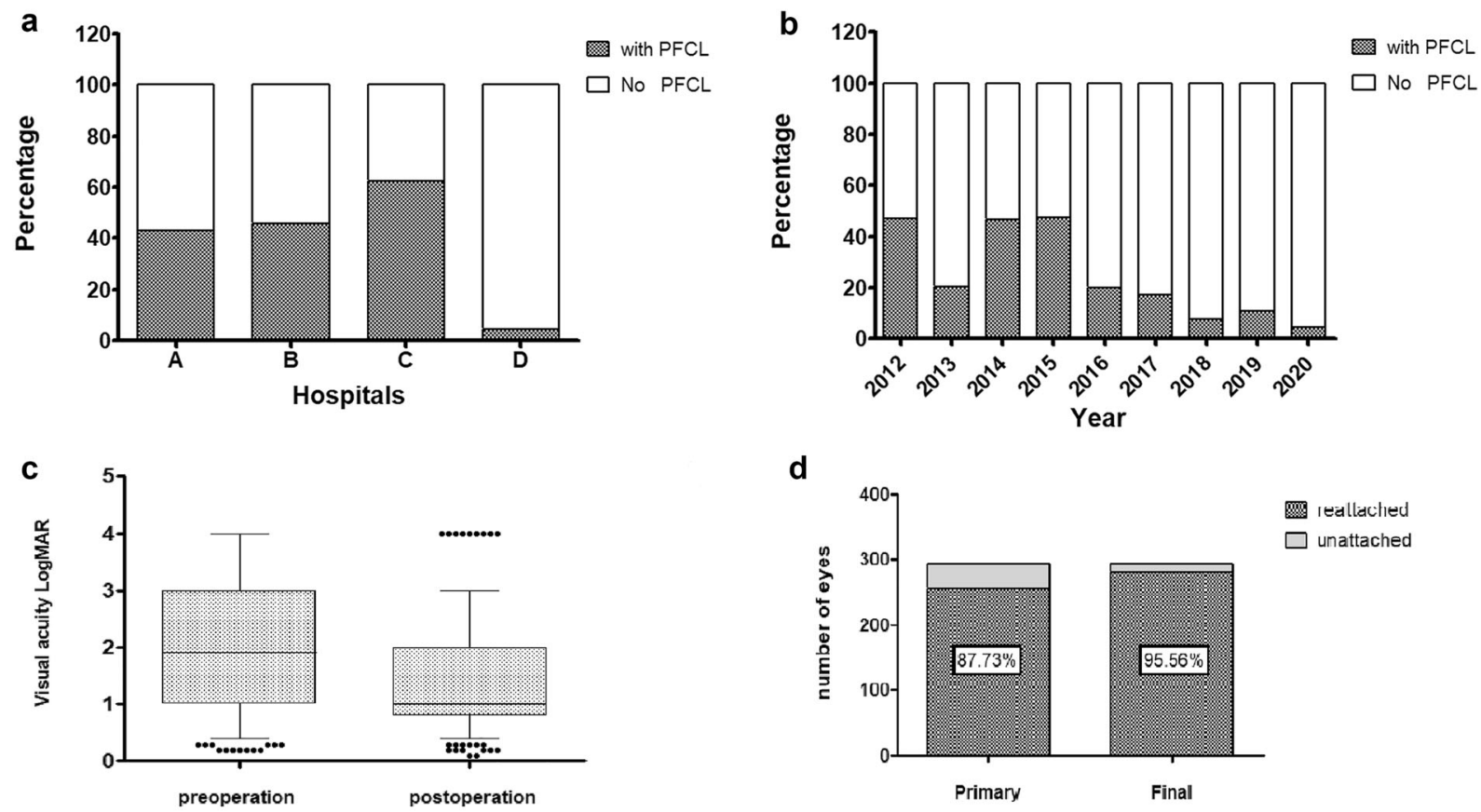

Fig. 1 Utilisation of PFCL in the real world and outcomes of VWTPL. a The proportion of PFCL utilisation varied amongst the four hospitals in 2020. b The annual proportion of PFCL utilisation in one hospital varied from 2012 to 2020. c For the 320 eyes subjected to VWTPL, postoperative VA was better than

positive results were subjected to binary logistic regression analysis to identify the factors predictive of RR.

The surgical results of procedures with or without PFCL were not compared because the baseline states were not equal.

\section{RESULTS}

\section{Procedure of VWTPL}

The procedure of VWTPL was presented in supplementary video 1 (see video 1 in the online/HTML version of the manuscript), and the air-fluid exchange was presented in supplementary video 2 (see video 2 in the online/ HTML version of the manuscript).

preoperative VA $(1.96 \pm 1.07$ vs. $1.43 \pm 0.92$, Log MAR, $p<0.001$, ${ }^{*}$ abnormal values). d For the 293 followed-up eyes, the primary and final retinal reattachment rates were $87.37 \%$ and $95.56 \%$, respectively (PFCL perfluorocarbon liquid, VWTPL vitrectomy without the aid of perfluorocarbon liquid)

\section{Real-World Application of PFCL}

The percentage of PFCL utilisation in the four hospitals was $42.74 \%$ (624/1460), 45.83\% (33/ $72), \quad 62.39 \%(287 / 460)$ and $4.5 \% \quad(8 / 178$; $p<0.001$, chi-square test; Fig. $1 \mathrm{a})$, with an overall percentage of $43.87 \%(952 / 2170)$. In the fourth hospital, the utilisation of PFCL per year was $46.94 \%, 20.43 \%, 46.73 \%, 47.41 \%, 20 \%$, $17.24 \%, 7.60 \%, 10.67 \%$ and $4.49 \%$ from 2012 to 2020 ( $p<0.001$, chi-square test; Fig. $1 b$ ).

\section{Ocular Conditions of 320 Eyes Receiving VWTPL}

The patients enrolled were 14-82 (mean: $49.82 \pm 14.31$ ) years old and Chinese, including 152 (47.50\%) females and 168 (52.50\%) males. A total of 320 eyes suffered from CRD, including 103 with high myopia, 12 with choroid detachment, 20 with giant tear, 26 with 


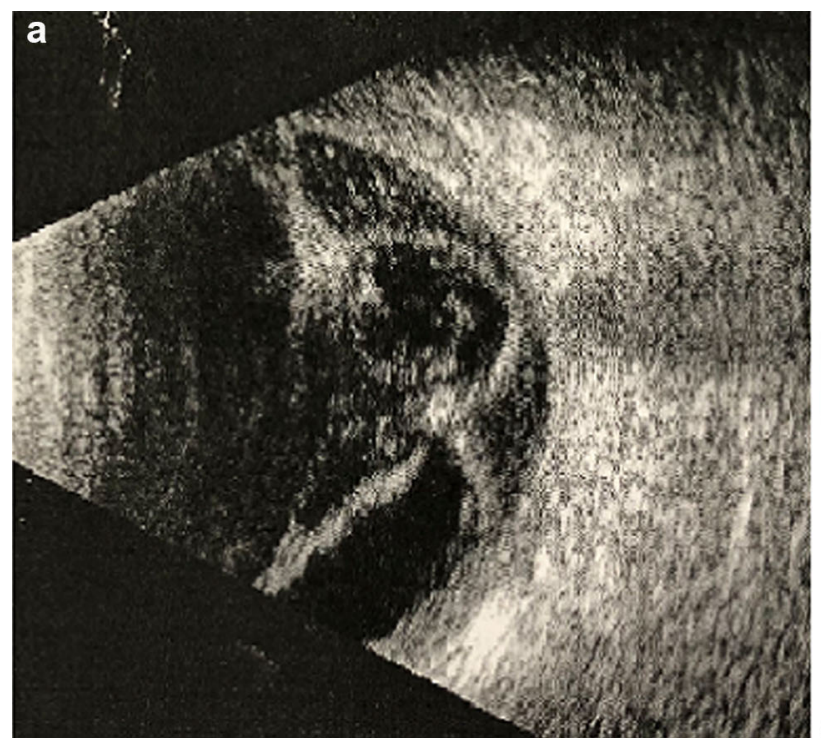

Fig. 2 Ocular examinations of a CRD patient treated by VWTPL. a Preoperative B ultra-scanning of the left eye showed fixed funnel-shaped RD. VA was based on hand movement ( $\log$ MAR > 2). The fundus photography was unobtainable because of complicated cataract. The patient

macular hole, 285 with PVR CP a-c, 145 with PVR CA a-b, 35 with PDR, 80 with ocular surgery history (24 underwent vitrectomy + cataract extraction, three underwent vitrectomy + scleral buckling and others underwent only vitrectomy, cataract extraction or SB), 44 with ocular traumatic history, 29 with uveitis and 17 with recurrent RD. The macular area was detached in all eyes. In addition, one patient underwent chemotherapy for malignant tumour, and two eyes showed congenital choroid defect. Ocular conditions of a CRD patient are illustrated in Fig. 2.

\section{Vision Recovery and Influencing Factors}

Early postoperative VA was tested 1 week after VTWPL. The 320 eyes showed better VA than those before surgery $(1.96 \pm 1.07$ vs. $1.43 \pm 0.92, \log \mathrm{MAR}, p<0.001$, Fig. 1c).

Analyses of the factors that may influence postoperative VA showed that age, uveitis, recurrent $\mathrm{RD}$, the number of detached retinal quadrant, aPVR and preoperative LogMAR VA

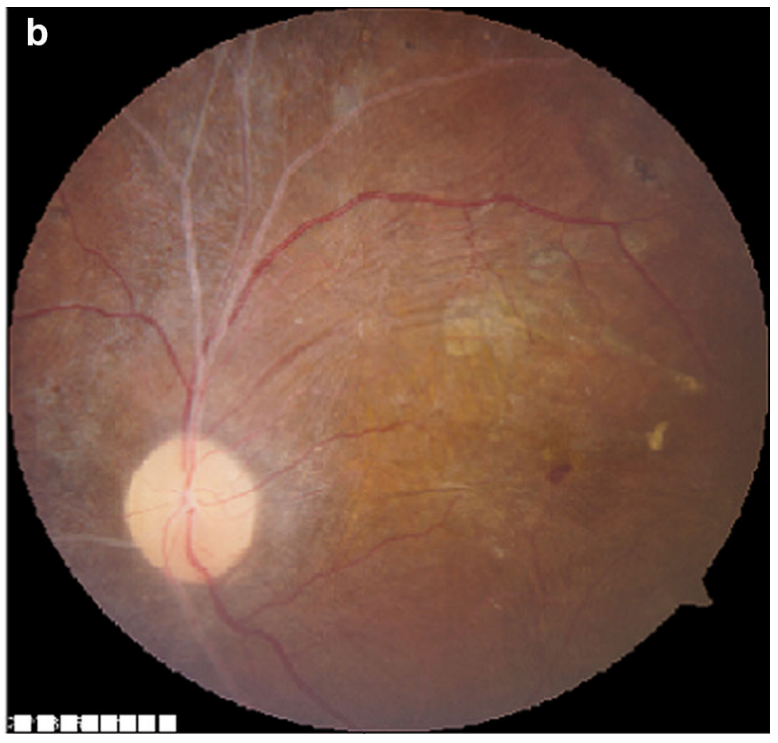

received VWTPL together with phacoemulsification and silicone oil tamponade. b The fundus photography showed retinal reattachment of the eye 3 months after silicone oil removal and intraocular lens implantation. The BCVA (Log MAR) was 0.8

correlated with VA 1 week after the operation (Table 1).

Ordinal logistic regression test showed that uveitis $(p=0.005, \quad \mathrm{OR}=0.07)$, recurrent $\mathrm{RD}$ $(p=0.06, \quad \mathrm{OR}=6.37)$, aPVR $(p=0.006, \quad \mathrm{OR}=$ $0.29)$ and preoperative LogMAR VA $(p=0.001$, $\mathrm{OR}=0.53$ ) were independent factors predicting VA 1 week after the operation.

\section{RR and Influencing Factors}

Amongst the 320 eyes subjected to VWTPL, 305 (95.31\%) had retinal reattachment immediately after the operation. The reasons for the failure of retinal reattachment included retinal contraction, hemorrhage, postoperative proliferation, etc. Patients were followed up for 1-26 months, and 27 eye cases lost contact. The remaining 293 cases had a mean age of $50.86 \pm 14.08 \quad(15-82)$ years, including 147 males and 146 females, and they were followed up for 1-26 (median: 9) months. During followups, retinal redetachment occurred in 22 silicone-oil-filled eyes. Except for the 27 lost eye 
Table 1 Factors influencing postoperative VA of the 320 eyes subjected to VWTPL

\begin{tabular}{|c|c|c|c|c|c|c|}
\hline \multirow[t]{2}{*}{ Factor } & \multirow[t]{2}{*}{ Groups } & \multicolumn{3}{|l|}{ VA } & \multirow[t]{2}{*}{ Statistics } & \multirow[t]{2}{*}{$p$ value } \\
\hline & & Increase & Unchanged & Decrease & & \\
\hline \multirow[t]{2}{*}{ Gender } & Male & 87 & 72 & 9 & $\chi^{2}$ & 0.15 \\
\hline & Female & 64 & 74 & 14 & & \\
\hline Age (mean $\pm S D$, years $)$ & & $50.61 \pm 12.15$ & $47.09 \pm 16.65$ & $59.56 \pm 4.93$ & ANOVA & 0.00 \\
\hline \multirow[t]{2}{*}{ Eye } & Right & 74 & 54 & 12 & $\chi^{2}$ & 0.10 \\
\hline & Left & 77 & 92 & 11 & & \\
\hline \multirow[t]{2}{*}{ Ocular trauma } & Yes & 20 & 24 & 0 & $\mathrm{~K}$ & 0.10 \\
\hline & No & 131 & 122 & 23 & & \\
\hline \multirow[t]{2}{*}{ High myopia } & Yes & 46 & 53 & 4 & $\chi^{2}$ & 0.16 \\
\hline & No & 105 & 93 & 19 & & \\
\hline \multirow[t]{2}{*}{ Uveitis } & Yes & 26 & 3 & 0 & $\mathrm{~K}$ & 0.00 \\
\hline & No & 125 & 143 & 23 & & \\
\hline \multirow[t]{2}{*}{ Ocular surgery } & Yes & 40 & 38 & 2 & $\chi^{2}$ & 0.17 \\
\hline & No & 111 & 108 & 21 & & \\
\hline \multirow[t]{3}{*}{ Lens } & Phakia & 128 & 123 & 23 & $\mathrm{~K}$ & 0.13 \\
\hline & Pseudophakia & 20 & 20 & 0 & & \\
\hline & Aphakia & 3 & 3 & 0 & & \\
\hline \multirow[t]{2}{*}{ Choroida detachment } & Yes & 6 & 6 & 0 & $\mathrm{~K}$ & 0.63 \\
\hline & No & 145 & 140 & 23 & & \\
\hline \multirow[t]{2}{*}{ Recurrent RD } & Yes & 0 & 12 & 5 & $\mathrm{~K}$ & 0.00 \\
\hline & No & 151 & 134 & 18 & & \\
\hline \multirow[t]{4}{*}{ Detached quadrants } & 1 & 30 & 17 & 5 & $\mathrm{~K}$ & 0.00 \\
\hline & 2 & 62 & 53 & 15 & & \\
\hline & 3 & 19 & 23 & 0 & & \\
\hline & 4 & 40 & 53 & 3 & & \\
\hline \multirow[t]{2}{*}{ Macular hole } & Yes & 10 & 16 & 0 & $\mathrm{~K}$ & 0.13 \\
\hline & No & 141 & 130 & 23 & & \\
\hline \multirow[t]{2}{*}{ Giant tear } & Yes & 12 & 8 & 0 & $\mathrm{~K}$ & 0.30 \\
\hline & No & 139 & 138 & 23 & & \\
\hline
\end{tabular}


Table 1 continued

\begin{tabular}{|c|c|c|c|c|c|c|}
\hline \multirow[t]{2}{*}{ Factor } & \multirow[t]{2}{*}{ Groups } & \multicolumn{3}{|l|}{ VA } & \multirow[t]{2}{*}{ Statistics } & \multirow[t]{2}{*}{$p$ value } \\
\hline & & Increase & Unchanged & Decrease & & \\
\hline \multirow[t]{5}{*}{ No. of quadrants with hole } & 0 & 58 & 65 & 10 & \multirow[t]{5}{*}{$\mathrm{K}$} & \multirow[t]{5}{*}{0.49} \\
\hline & 1 & 70 & 63 & 11 & & \\
\hline & 2 & 18 & 11 & 2 & & \\
\hline & 3 & 0 & 5 & 0 & & \\
\hline & 4 & 5 & 2 & 0 & & \\
\hline \multirow[t]{2}{*}{ Posterior PVR (CP a-c) } & Yes & 135 & 131 & 19 & \multirow[t]{2}{*}{$\mathrm{K}$} & \multirow[t]{2}{*}{0.59} \\
\hline & No & 16 & 15 & 4 & & \\
\hline \multirow[t]{2}{*}{ Anterior PVR (CA a-b) } & Yes & 20 & 47 & 7 & \multirow[t]{2}{*}{$\chi^{2}$} & \multirow[t]{2}{*}{0.00} \\
\hline & No & 131 & 99 & 16 & & \\
\hline \multirow[t]{2}{*}{ PDR } & Yes & 21 & 12 & 2 & \multirow[t]{2}{*}{ K } & \multirow[t]{2}{*}{0.28} \\
\hline & No & 130 & 134 & 21 & & \\
\hline Course of RD, (days) & Median/mean rank & $12 / 139.41$ & $23 / 175.20$ & $60 / 205.67$ & $\mathrm{~K}$ & 0.00 \\
\hline Preoperative VA, (LogMAR) & Median/mean rank & $2 / 175.57$ & $1.75 / 147.50$ & $1.7 / 144.09$ & $\mathrm{~K}$ & 0.02 \\
\hline Preoperative IOP, (mmHg) & Median/mean rank & $10.5 / 156.11$ & $10.7 / 159.05$ & $13 / 198.05$ & K & 0.12 \\
\hline
\end{tabular}

$\chi^{2}$ chi-square test, $K$ Kruskal-Wallis test, ANOVA analyses of variance

$P<0.05$ was considered statistically significant

cases, the primary RR rate was $87.37 \%(256 / 293$, Fig. 1d).

Amongst the 15 eyes whose retina was not restored immediately after VWTPL, five received a second VWTPL, which restored the retina, whereas the other ten eye cases refused a second VWTPL and remained unchanged until the last follow-up. All 22 eyes with retinal redetachment underwent second VWTPL, which restored the retina in 19 eyes, whereas 3 eyes were detached in situ. A total of 13 eyes had failed retinal restoration. Except for the 27 lost eye cases, the final RR rate was 95.56\% (280/ 293, Fig. 1d).

Analyses of the factors that may influence RR showed that preoperative LogMAR VA and preoperative IOP influenced the primary RR. Low VA (high LogMAR) and low IOP may impede retinal restoration (Table 2 ).

\section{DISCUSSION}

CRD is difficult to handle because of the accompanying pathological conditions. PPV is better than SB with improved postoperative VA in the treatment of pseudophakic/aphakic RDs $[15,16]$, although the primary and final RR rates could hardly achieve $100 \%$.

PFCLs are commonly used during PPV. According to this study, PFCL utilisation varied from 4.5 to $62.39 \%$. In our hospital, where PFCL was used the least in 2020, PFCL utilisation has tended to decrease over the past 9 years. Thus, we utilised micro-incision PPV to avoid the above-mentioned PFCL-related complications. This procedure can achieve high-speed cutting and maintain a stable IOP, thereby smoothening out the retina by the surface tension of the gas with gas-fluid exchange without the use of PFCL [17]. This procedure is called VWTPL. All tractions and proliferations should be relieved 
Table 2 Factors influencing the primary retinal reattachment of 293 eyes subjected to VWTPL

\begin{tabular}{|c|c|c|c|c|c|}
\hline Factor & Groups & Reattached eyes & Unattached eyes & Statistics & $p$ \\
\hline & Total & $256(87.37 \%)$ & $37(12.63 \%)$ & & \\
\hline \multirow[t]{2}{*}{ Gender } & Male & 124 & 23 & $\chi^{2}$ & 0.16 \\
\hline & Female & 132 & 14 & & \\
\hline Age (mean $\pm S D$, years $)$ & & $51.05 \pm 13.96$ & $49.14 \pm 16.23$ & $t$ & 0.35 \\
\hline \multirow[t]{2}{*}{ Eyes } & Right & 106 & 21 & $\chi^{2}$ & 0.08 \\
\hline & Left & 150 & 16 & & \\
\hline \multirow[t]{2}{*}{ Ocular trauma } & Yes & 29 & 8 & $\chi^{2}$ & 0.11 \\
\hline & No & 227 & 29 & & \\
\hline \multirow[t]{2}{*}{ High myopia } & Yes & 83 & 12 & $\chi^{2}$ & 0.99 \\
\hline & No & 173 & 25 & & \\
\hline \multirow[t]{2}{*}{ Uveitis } & Yes & 24 & 2 & $\chi^{2}$ & 0.55 \\
\hline & No & 232 & 35 & & \\
\hline \multirow[t]{2}{*}{ Ocular surgery } & Yes & 64 & 10 & $\chi^{2}$ & 0.79 \\
\hline & No & 192 & 27 & & \\
\hline \multirow[t]{3}{*}{ Len } & Phakia & 217 & 32 & $\mathrm{~K}$ & 0.75 \\
\hline & Pseudophakia & 33 & 5 & & \\
\hline & Aphakia & 6 & 0 & & \\
\hline \multirow[t]{2}{*}{ Choroidal detachment } & Yes & 9 & 1 & $\chi^{2}$ & 1.00 \\
\hline & No & 247 & 36 & & \\
\hline \multirow[t]{2}{*}{ Recurrent RD } & Yes & 13 & 2 & $\chi^{2}$ & 1.00 \\
\hline & No & 243 & 35 & & \\
\hline \multirow[t]{4}{*}{ Detached area (quadrants) } & 1 & 47 & 3 & $\mathrm{~K}$ & 0.09 \\
\hline & 2 & 104 & 15 & & \\
\hline & 3 & 32 & 4 & & \\
\hline & 4 & 73 & 15 & & \\
\hline \multirow[t]{2}{*}{ Macular hole } & Yes & 21 & 4 & $\chi^{2}$ & 0.54 \\
\hline & No & 235 & 33 & & \\
\hline \multirow[t]{2}{*}{ Giant tear } & Yes & 17 & 2 & $\chi^{2}$ & 1.00 \\
\hline & No & 239 & 35 & & \\
\hline
\end{tabular}


Table 2 continued

\begin{tabular}{llllll}
\hline Factor & Groups & Reattached eyes & Unattached eyes & Statistics & $\boldsymbol{p}$ \\
\hline Quadrants with holes & 0 & 110 & 11 & $\mathrm{~K}$ & 0.07 \\
& 1 & 116 & 18 & & \\
& 2 & 21 & 7 & & \\
& 3 & 4 & 0 & & \\
& 4 & 5 & 1 & & \\
Posterior PVR (CP a-c) & Yes & 227 & 32 & & 0.78 \\
& No & 29 & 5 & & \\
Anterior PVR (CA a-b) & Yes & 54 & 11 & $\chi^{2}$ & 0.24 \\
PDR & No & 202 & 26 & & \\
& Yes & 28 & 1 & $\chi^{2}$ & 0.15 \\
Course of disease, days (median/mean rank) & No & 228 & 36 & & \\
Preoperative VA, LogMAR (median/mean rank) & & $20.5 / 149.86$ & $14 / 127.19$ & $\mathrm{U}$ & 0.13 \\
Preoperative IOP (median/mean rank) & & $1.8 / 143.03$ & $3.0 / 174.47$ & $\mathrm{U}$ & $\mathbf{0 . 0 3}$ \\
\hline
\end{tabular}

$\chi^{2}$ chi-square test, $t$ t-test, $K$ Kruskal-Wallis test, $U$ Mann-Whitney $U$ test; $p$ value $P<0.05$ was considered statistically significant

Table 3 Summary of surgical outcomes for RD

\begin{tabular}{lcllllllll}
\hline Author & Cases & PPV & PL & $\begin{array}{l}\text { PRR } \\
\%\end{array}$ & $\begin{array}{l}\text { FRR } \\
\%\end{array}$ & $\begin{array}{l}\text { Preoperative VA } \\
\text { LogMAR }\end{array}$ & $\begin{array}{l}\text { Postoperative } \\
\text { VA } \\
\text { LogMAR }\end{array}$ & $p$ value & Reference \\
\hline Chiharu & 27 & $25 \mathrm{G}$ & No & 77.80 & 92.60 & $1.36 \pm 0.81$ & $0.75 \pm 0.78$ & $<0.001$ & {$[18]$} \\
Paraschos & 51 & $20 / 23 \mathrm{G}$ & No & 80.00 & 84.00 & $2.45 \pm 0.66$ & $1.37 \pm 0.75$ & 0.001 & {$[19]$} \\
Liu & 21 & - & Some & - & 90.50 & $1.93 \pm 0.48$ & $1.52 \pm 0.45$ & 0.001 & {$[20]$} \\
Mohammad & 370 & P/20/ & All & 84.50 & 92.97 & $2.33 \pm 0.83$ & $1.48 \pm 0.92$ & $<0.001$ & {$[21]$} \\
& & $23 G$ & & & & & & & \\
Our study & 128 & $23 \mathrm{G}$ & No & 86.44 & 95.76 & $1.97 \pm 1.06$ & $1.43 \pm 0.92$ & $<0.001$ & \\
\hline
\end{tabular}

- unknown, $P R R$ primary reattachment rate, $F R R$ final reattachment rate

before gas-fluid exchange. In our study, comparative analysis was not applied because the number of cases with PFCL was fewer than those without PFCL. The evaluation of postoperative VA and RR rates showed similar or better results than previously reported [18-21] (Table 3), though the study group was not equivalent to those studies; these results 
suggested that VMTPL is a sound stratagem. A comparative study comparing the use of PFCL and subretinal fluid drainage reported a $90.7 \%$ PRR and 100\% FRR for both groups [22].

In our study, retina was unattached in 13 eyes, 10 of which occurred in the inferior peripheral area. This result may be due to the proliferative stiffening and horizontal traction of the local retina. A combination of SB [23], heavy silicone oil tamponade [24] or retinotomy [25] may be used.

Factors associated with RR failure include choroid detachment, considerable hypotony, PVR, total RD, large retinal breaks [26] and extent of retinectomy [27]. The presence of preoperative PVR and the development of postoperative PVR primarily contributed to the failure of RR $[28,29]$. In our study, low preoperative VA and decreased preoperative IOP were considered as factors unfavourable to RR in VWTPL treatment. Low IOP and a large detachment area may hamper the 'pump function' of retinal pigment epithelium and decrease the adhesion of the interphotoreceptor matrix [30, 31], making retinal replacement difficult. Though not demonstrated in our study, the factor 'young age' may be an unfavourable factor for RR because young people have a high risk of developing PVR because the younger the patient is, the higher the ability of self-repair of retinal tissues [32]. Although not evaluated in our study, 'surgical experience' is also a substantial factor indicating the success rate [27].

The factors that are favourable to postoperative VA include reattached retina (particularly macula), slight $\mathrm{P}(\mathrm{D}) \mathrm{VR}$, good preoperative VA, postoperative shape of the macular fovea and regular distribution of laser spots [27]. Intraoperative photocoagulation may decrease the possibility for retinal redetachment and aid the recovery of VA [4]. By contrast, the factors that are unfavourable to postoperative VA include rhegmatogenous $\mathrm{RD}$, transverse trauma, inflammation (endophthalmitis, uveitis, retinitis, etc.) and preoperative PVR, particularly its grading. Our study on VWTPL surgery showed similar results. For example, recurrent RD, anterior PVR and worse preoperative VA are factors unfavourable to postoperative VA of patients with RD treated with VWTPL. Furthermore, although uveitis is unfavourable to RR, it was related to a good prognosis of postoperative VA.

The limitation of this study is that no randomised comparative design was applied because of the imbalance between sample sizes. There are relevant biases related to the retrospective study and a long-term VA results need to be analysed. Also, the study population is somewhat heterogeneous due to the simplex selection criteria.

\section{CONCLUSIONS}

In this study, the utilisation of PFCL varies amongst hospitals, and it can be spared in most cases. VWTPL is an effective and efficient surgical treatment for CRD, thereby saving the use of PL and avoiding related complications.

\section{ACKNOWLEDGEMENTS}

Funding. Sponsorship for this study, and the journal's Rapid Service Fee, were funded by the Technical Innovation Foundation for Clinical Medicine by Jinan Science and Technology Bureau (grant no. 201704122), the Department of Science and Technology of Shandong Province (grant no. ZR201702190277) and the Research Start-up Funds for Introduced Talents by the Second Hospital of Shandong University (YY-2021-001). The funders had no role in the study design, data collection and analysis, decision to publish or preparation of the manuscript.

Authorship. All named authors meet the International Committee of Medical Journal Editors (ICMJE) criteria for authorship for this article, take responsibility for the integrity of the work as a whole, and have given their approval for this version to be published.

Author Contributions. Xue-Jiao Qin and Qi Song designed the study. Xue-Jiao Qin, HMC and Ye Bai were the major contributors to the 
writing of the manuscript. Ye Bai, Qin-Xing Wu and Xue-Jiao Qin carried out the operations. Ye Bai, Qi Song and Qin-Xing $\mathrm{Wu}$ enrolled and managed the patients. Ye Bai and Jing Liu analysed and interpreted the data. All authors read and approved the final manuscript.

Disclosures. Ye Bai, Qi Song, Jing Liu, QinXing $\mathrm{Wu}$ and Xue-Jiao Qin declare that they have no conflict of interest.

Compliance with Ethics Guidelines. The study complies with the protocols reviewed and approved by the Independent Ethics Committee on Scientific Research of Shandong University, Qilu Hospital and the tenets of the Helsinki Declaration of 1964 (and its later amendments). The clinical trial registration number of this study is ChiCTR-ORC-17014225. Signed informed consent was obtained from all participants and the parent or guardian for participants under 16 years old.

Data Availability. The datasets generated during and/or analysed during the current study are available from the corresponding author on reasonable request.

Open Access. This article is licensed under a Creative Commons Attribution-NonCommercial 4.0 International License, which permits any non-commercial use, sharing, adaptation, distribution and reproduction in any medium or format, as long as you give appropriate credit to the original author(s) and the source, provide a link to the Creative Commons licence, and indicate if changes were made. The images or other third party material in this article are included in the article's Creative Commons licence, unless indicated otherwise in a credit line to the material. If material is not included in the article's Creative Commons licence and your intended use is not permitted by statutory regulation or exceeds the permitted use, you will need to obtain permission directly from the copyright holder. To view a copy of this licence, visit http://creativecommons.org/licenses/by$\mathrm{nc} / 4.0 /$.

\section{REFERENCES}

1. Wei Y, Li Y, Chen F. Vitrectomy treatment of retinal detachments related to choroidal coloboma involving the disk. Retina. 2014;34(6):1091-5.

2. Gonzalez MA, Flynn HW Jr, Smiddy WE, Albini TA, Tenzel P. Surgery for retinal detachment in patients with giant retinal tear: etiologies, management strategies, and outcomes. Ophthalmic Surg Lasers Imaging Retina. 2013;44(3):232-7.

3. Sato T, Emi K, Bando H, Ikeda T. Retrospective comparison of 25-gauge vitrectomy for repair of proliferative vitreoretinopathy with or without anterior proliferation. Graefes Arch Clin Exp Ophthalmol. 2014;252(12):1895-902.

4. de Silva DJ, Kwan A, Bunce C, Bainbridge J. Predicting visual outcome following retinectomy for retinal detachment. Br J Ophthalmol. 2008;92(7): 954-8.

5. Chang S. Low viscosity liquid fluorochemicals in vitreous surgery. Am J Ophthalmol. 1987;103(1): $38-43$.

6. Rush R, Simunovic MP, Sheth S, Chang A, Hunyor AP. 23-Gauge pars plana vitrectomy versus scleral buckling versus combined pars plana vitrectomyscleral buckling for medium-complexity retinal detachment repair. Asia Pac J Ophthalmol. 2014;3(4):215-9.

7. Gu X, Hu Z, Qian H, Fransisca S, Mugisha A, Wang $\mathrm{J}$, et al. Perfluorocarbon liquid-assisted inverted internal limiting membrane flap technique versus internal limiting membrane peeling for highly myopic macular hole retinal detachment. Retina. 2021;41(2):317-23.

8. Figueroa MS, Casas DR. Inflammation induced by perfluorocarbon liquid: intra- and postoperative use. BioMed Res Int 2014(2314-6141 (Electronic)): Article ID 907816.

9. Marafon SB, Juncal VR, Muni RH. Retinal shift with perfluorocarbon liquid without air-fluid exchange. Ophthalmology. 2020;127(5):598.

10. Lorenzi U, Mora P, Luciani E, Barale PO, Muraine M. Treatment of subretinal perfluorocarbon liquid bubbles complicating retinal detachment surgery using air for drainage. Retin Cases $\mathrm{Br}$ Rep. 2020;28(7). https://doi.org/10.1097/ICB.00000000 00001023.

11. Bastawrous A, Kumar V. 'Bubbles in my eye'. Perfluorocarbon liquid residue in the anterior chamber. Clin Exp Optom. 2012;95(5):555-6. 
12. Naseripour M, Ghasempour A, Falavarjani KG, Sanjari MS, Yousefi M. Perfluorocarbon liquid migration into the subarachnoid space in a patient with morning glory syndrome. J Curr Ophthalmol. 2015;27(1-2):60-2.

13. Georgalas I, Ladas I, Tservakis I, Taliantzis S, Gotzaridis E, Papaconstantinou D, et al. Perfluorocarbon liquids in vitreoretinal surgery: a review of applications and toxicity. Cutan Ocul Toxicol. 2011;30(4):251-62.

14. Mendez-Martinez S, Calvo P, Rodriguez-Marco NA, Faus F, Abecia E, Pablo L. Blindness related to presumed retinal toxicity after using perfluorocarbon liquid during vitreoretinal surgery. Retina. 2018;38(9):1856-64.

15. Soni C, Hainsworth DP, Almony A. Surgical management of rhegmatogenous retinal detachment: a meta-analysis of randomized controlled trials. Ophthalmology. 2013;120(7):1440-7.

16. Sun Q, Sun T, Xu Y, Yang XL, Xu X, Wang BS, et al. Primary vitrectomy versus scleral buckling for the treatment of rhegmatogenous retinal detachment: a meta-analysis of randomized controlled clinical trials. Curr Eye Res. 2012;37(6):492-9.

17. Coppola M, Marchese A, Cicinelli MV, La Spina C, Rabiolo A, Bandello F. Letter to the editor: perfluorocarbon-free vitrectomy for rhegmatogenous retinal detachment: feasibility and outcomes in the small-gauges era. Curr Eye Res. 2019;44(8):925-6.

18. Iwahashi-Shima C, Sato T, Bando H, Ikeda T, Emi K. Anatomic and functional outcomes of 25-gauge vitrectomy for repair of eyes with rhegmatogenous retinal detachment complicated by proliferative vitreoretinopathy. Clin Ophthalmol. 2013;7: 2043-9.

19. Tranos P, Vakalis A, Asteriadis S, Lokovitis E, Georgalas I, Stavrakas P. Anatomic and functional outcomes of retinectomy for the management of complicated retinal detachment with proliferative vitreoretinopathy. Ther Clin Risk Manag. 2015;11: 1515-21.

20. Liu F, Li H, Feng L, Wang F. Anatomical and functional outcomes after Densiron 68 heavy silicone oil tamponade for complicated retinal detachment in Chinese eyes. Int J Ophthalmol. 2014;7(3): 469-73.

21. Adhi MI, Siyal N, Aziz S. Anatomical and functional outcomes of retinectomies in retinal detachments complicated by proliferative vitreoretinopathy. Saudi J Ophthalmol. 2017;31(4):216-23.
22. Vidne O, Blum Meirovitch S, Rabina G, Abd Eelka$\operatorname{der}$ A, Prat D, Barequet D, et al. Perfluorocarbon liquid vs. subretinal fluid drainage during vitrectomy for the primary repair of rhegmatogenous retinal detachment: a comparative study. Curr Eye Res. 2018;43(11):1389-94.

23. Goezinne F, La Heij EC, Berendschot TTJM, Gast STJM, Liem ATA, Lundqvist IL, et al. Low redetachment rate due to encircling scleral buckle in giant retinal tears treated with vitrectomy and silicone oil. Retina. 2008;28(3):485-92.

24. Levasseur SD, Schendel S, Machuck RWA, Dhanda D. High-density silicone oil densiron-68 as an intraocular tamponade for primary inferior retinal detachments. Retina. 2013;33(3):627-33.

25. Sheng Y, Sun W, Mo B, Yu YJ, Gu YS, Liu W. Nonbuckled vitrectomy for retinal detachment with inferior breaks and proliferative vitreoretinophathy. Int J Ophthalmol. 2012;5(5):591-5.

26. Adelman RA, Parnes AJ, Michalewska Z, Ducournau D, European Vitreo-Retinal Society Retinal Detachment Study G. Clinical variables associated with failure of retinal detachment repair: the European vitreo-retinal society retinal detachment study report number 4. Ophthalmology. 2014;121(9): $1715-9$.

27. Deuchler S, Ackermann $\mathrm{H}$, Singh $\mathrm{P}$, Kohnen $\mathrm{T}$, Wagner C, Koch F. Key factors to improve the outcome of retinal reattachment surgery in proliferative vitreoretinopathy and proliferative diabetic retinopathy. J Ophthalmol. 2017;2017:2323897.

28. Girard P, Mimoun G, Karpouzas I, Montefiore G. Clinical risk factors for proliferative vitreoretinopathy after retinal detachment surgery. Retina. 1994;14(5):417-24.

29. Enders P, Schick T, Schaub F, Kemper C, Fauser S. Risk of multiple recurring retinal detachment after primary rhegmatogenous retinal detachment repair. Retina. 2017;37(5):930-5.

30. Cantrill H, Pederson JE. Experimental retinal detachment. VI. The permeability of the bloodretinal barrier. Arch Ophthalmol. 1984;102(5): 747-51.

31. Hageman GS, Marmor MF, Yao XY, Johnson LV. The interphotoreceptor matrix mediates primate retinal adhesion. Arch Ophthalmol. 1995;113(5): 655-60.

32. Al-Zaaidi S, Al-Rashaed S, Al-Harthi E, Al-Kahtani E, Abu El-Asrar AM. Rhegmatogenous retinal detachment in children 16 years of age or younger. Clin Ophthalmol. 2013;7:1001-14. 